Island Studies Journal, Vol. 7, No. 2, 2012, pp. 235-258

\title{
‘Genuine Jersey’: Branding and Authenticity in a Small Island Culture
}

\author{
Henry Johnson \\ University of Otago \\ New Zealand \\ henry.johnson@otago.ac.nz
}

\begin{abstract}
Jersey has attained a recognized international reputation especially in agriculture, tourism and finance. Over the past century, this small island has developed rapidly as a tourist destination and, since the 1960 s, as a leading international finance centre. This paper discusses how a public-private organization uses a notion of islandness in order to help add value to local produce and products, and at the same time offering a sense of authenticity in terms of provenance. As an organization and brand, "Genuine Jersey" was launched in 2001 and is now a particularly visible island-based brand that does much to support local businesses and promote selected island produce and products more broadly to locals and visitors alike, as well as within a wider export industry. Drawing on discourses mainly from island studies and marketing, the article discusses how and why this brand exists on Jersey. While including a critical discussion of the brand itself, the paper shows how Genuine Jersey operates on and as a result of this particular island context.
\end{abstract}

Keywords: authenticity, branding, Genuine Jersey, island, Jersey, produce, products, publicprivate partnership

(C) 2012 Institute of Island Studies, University of Prince Edward Island, Canada

\section{Introduction}

This paper studies the interconnection between branding and constructions of authenticity on Jersey. The aim of the article is to show how one organization on a small island utilizes a notion of islandness in several ways in order to help add value in terms of provenance to select local produce and products. The organization functions in this context through an interconnection with government and business in a way that is constructed as a result of its specific island context. It is here that this paper provides a critical discussion of not only how such branding occurs in this island setting, but also how the island itself adds value when positioning local produce and products.

As a relatively small island with a land area of about $118 \mathrm{~km}^{2}$ (States of Jersey Statistics Unit, 2010: iii) and a population in 2011 of 97,857 (States of Jersey Statistics Unit, 2012: 2), Jersey boomed as a tourist destination in the decades following the Second World War, especially with visitors from the United Kingdom who were attracted by such features as its warmer climate, low taxes and natural tourist attractions. Jersey is approximately $137 \mathrm{~km}$ from England and $23 \mathrm{~km}$ from France (States of Jersey Statistics Unit, 2010: iii). However, the mass tourism the island once experienced declined rapidly in the 1990s under pressure from other tourist destinations as a result of increased and cheaper travel options. In its place, and ever growing from the 1960s, finance has now become Jersey's main industry. For a small island, the 


\section{H. Johnson}

physical landscape has subsequently been altered in that many hotels that once housed decades of visiting tourists have now been replaced by apartment blocks for the growing permanent and temporary workers that dominate the island's business sector (Lichrou et al., 2010: 139).

Jersey has its own government (the States of Jersey), laws, taxes, endangered language and various other aspects of governance and cultural heritage that contribute to making the island what it is today. Each helps form the Jersey brand. Nevertheless, even though some features of Jersey's heritage are foregrounded in tourism and other contexts of island celebration, such as British and German military defences (the island was occupied by Nazi Germany from 1940 to 1945), it is an identity that is actually constructed from a diverse population and increased external influences. For example, based on figures from the last official census in 2011, the place of birth of Jersey's population showed mixed influences that were the result of recent migrations from the British Isles, the European mainland and further afield (Table 1).

\section{Table 1: Islanders’ Place of Birth (States of Jersey Statistics Unit, 2012: 9).}

\begin{tabular}{|l|c|c|}
\hline Place of Birth & Number of People & Percentage of Population \\
\hline Jersey & 48,653 & 50 \\
\hline British Isles & 30,223 & 31 \\
\hline Portugal/Madeira & 7,031 & 7 \\
\hline Poland & 3,133 & 3 \\
\hline Republic of Ireland & 1,880 & 2 \\
\hline Other European country & 3,146 & 3 \\
\hline Elsewhere in the world & 3,791 & 4 \\
\hline
\end{tabular}

In the broader setting of the European Union, of which Jersey is not a part (nor is it a part of the United Kingdom), ${ }^{1}$ as well as other outside influences, Jersey today makes much of its uniqueness as an island (e.g. location, size, history, politics) to celebrate its heritage and selfgoverning identity, particularly in the spheres of agriculture, tourism and finance. It is in this context that branding and constructions of authenticity interconnect to celebrate products that stand for Jersey. Selected goods, whether manufactured, grown or caught, are presented by Genuine Jersey (a public-private organization; also known as Genuine Jersey Products Association [GJPA] in full) as types of "cultural heritage assets" (Ivanovic, 2008: 215), and these items are given value and consumed by locals and visitors alike in a process that not only supports some local businesses, but also actively celebrates products that are considered unique to the island, whether well or recently established.

In connection with understanding these links, this paper discusses the Genuine Jersey brand, which was launched in 2001, as a case study for investigating critically some of the ways this small island culture celebrates and constructs notions of authenticity in its local economy. As a way of contributing to and extending the literature on the branding of islands (e.g. Baldacchino, 2005, 2010b; Grydehøj, 2008, 2010; Kelman, 2007; Khamis, 2010, 2011;

\footnotetext{
${ }^{1}$ As a British Crown Dependency, the Bailiwick of Jersey's relationship with the EU relates to certain limited provisions contained in Protocol 3 to the UK's Treaty of Accession to the European Economic Community (later European Union) in 1972. "In simple terms, the Island is treated as part of the European Community for the purposes of free trade in goods, but otherwise is not a part of the EU" (States of Jersey, 2012).
} 
Leseure, 2010; Lichrou, O’Malley \& Patterson, 2010; Pounder, 2010; and Reddy \& Singh, 2010), this paper offers a study of a public-private branding exercise of one organization that is based around the notion of the authenticity of the goods it supports and promotes. The activity is seen to be inherently based around place branding, goods branding and the construction of a notion of authenticity. The discussion raises questions in connection with the selection criteria of Genuine Jersey products, as well as pointing out contradictions inherent in the branding process itself. Why has a notion of authenticity been constructed? How can a public-private organization truly represent the wider island community? Who are the key players in this branding process? In this context, Genuine Jersey is seen to undertake a process of selecting certain Jersey produce and products to brand as genuine island goods, an activity that helps show characteristics of a commercial exercise that actually interconnects business and government. In doing this, the paper also provides an example of how a small island with a recent history enmeshed in the tourist industry is reinventing itself in an age of rapid change to the three main industries that have themselves often come to stand for the island: agriculture, tourism and finance (Table 2).

Table 2: Principal Industries in 2009 (States of Jersey, Jersey Facts and Figures).

\begin{tabular}{|c|c|}
\hline Principal industries (2009 figures) & \% of Gross Value Added \\
\hline Financial services & 43 \\
\hline Public administration & 8 \\
\hline Wholesale and retail & 7 \\
\hline Construction & 6 \\
\hline Tourism & 3 \\
\hline Agriculture & 2 \\
\hline Other business activities & 9 \\
\hline
\end{tabular}

This article draws broadly on case studies of and critical discourse on place branding from several scholarly fields, especially island studies (e.g. Baldacchino, 2010c; Grydehøj, 2008; 2010) and marketing (e.g. Askegaard \& Kjeldgaard, 2007; Manniche et al., 2009; Manniche \& Larsen, 2009). The article provides a case study of place and produce/product branding on Jersey. As Kavaratzis (2008: 51) has noted:

Places have long felt a need to differentiate themselves from each other, to assert their individuality in pursuit of various economic, political or socio-psychological objectives. The conscious attempt of governments to shape a specifically designed place identity and promote it to identified markets, whether external or internal, is almost as old as civic government itself.

In this setting, and building on Kavaratzis' points, this article shows that there are several layers of branding in the Jersey case, including island/place branding and product/produce branding. Each layer contributes to creating not only a public-private organization that brands a place and its goods as authentic, but also a branding proposition with a sense of islandness and 'othering' at its core. 


\section{H. Johnson}

Several research methods have been used for data collection and analysis. Secondary data have been important for assembling background information and gaining historical knowledge of key facts and figures, as well as comparing different types of case study approaches to similar topics (e.g. Khamis, 2010; 2011; Reddy \& Singh, 2010; Pounder, 2010; Witkowski \& Jones, 2006). The research also included a telephone interview in May 2011 with the Chief Executive Officer of Genuine Jersey. Undertaking one in-depth semi-structured key-informant interview was essential in this particular context (the interviewee is the person responsible for the day-today operations, and the subject of this article is on this organization). Such an approach is typical in the field of cultural biography (e.g. Parke 2002), although in the context of this article, rather than focussing on the person, emphasis was placed on the organization. In other words, this is a case study of one organization and relies on several sources of information: historical, verbal and observational. The interview was based on open-ended questions on such themes as background, organization, funding, purpose and activities. Consent was given to use names and quotes from the interview, on the basis that everything said was typical of a media interview that would be broadcast to the wider public.

Following a short section that contextualizes recent place branding in connection with Jersey from a politico-economic perspective, the main part of the discussion focuses on outlining and discussing the Genuine Jersey brand: its purpose, structure, logo and activities.

\section{Branding Jersey for the Tourist Gaze}

Many islands have utilized, rediscovered or even invented aspects of their heritage as part of a branding exercise. Grydehøj (2010), for example, explores the idea of heritage production in Shetland (Scotland), Åland (Finland) and Svalbard (Norway). In earlier research, and in connection with the influence of business, he points out that:

It is not just that marketers use marketing to disseminate a message about a product. The complex and evolving nature of the product (the place) itself and the marketers' frequent personal identification of themselves as part of the product means that the very process of place branding has the dual potential to inform policy makers and to intensify their prejudices (Grydehøj, 2008: 175).

Such research, as well as that mentioned in the introduction, shows that some small islands have made much of their environmental or cultural settings in terms of creating a place brand for the island, or for the promotion of local industry, including tourism and commercial goods.

The Jersey brand, however, has several guises, and has over the past sixty years or so been adapted in various ways. In terms of branding itself as a location (an island location), Jersey's main industries have been at the heart of each successive branding and re-branding exercise. While agriculture, tourism and finance have distinct historical and recent histories on the island, their presence and importance have impacted at different times and in different ways in connection with Jersey and place branding. Although a sixty-year period is a relatively short time span to consider, the changes that have occurred to Jersey's principal industries have been dramatic, and the decline of some (in place of the growth of others) is currently seen at a juncture where past successful industries have acquired a status akin to cultural heritage 
(Ivanovic, 2008: 215). That is, while their importance to the island's economy may have been transformed from principal to secondary status, they have maintained importance to a smaller yet still significant market, and at the same time attained status in terms of their heritage on Jersey as part of the Jersey brand in its broader guise.

As the most southerly inhabited island in the geographic British Isles (using a political definition of the term), ${ }^{2}$ Jersey boasts a milder and sunnier climate to the UK, and as such has been a traditional source for early agricultural crops and especially unique local produce such as the Jersey Royal Potato. Indeed, parts of the island itself have physically been re-defined as a result of centuries of farming, whether crops or dairy with the well-known Jersey cow. As the States of Jersey (i.e. Jersey's government) branding guide notes, "farming has shaped the beauty of Jersey's landscape and sustained local families over generations" (States of Jersey, 2007: n.p.; see also Corporate Edge Branding, 2008). This particular branding exercise was based around several questions relating to the promotion of Jersey: "How can we position Jersey as a sophisticated and contemporary place to visit? How can we reinforce perceptions of strength, solidity and integrity within the financial market? How can we help grow the agricultural sector in recognizing (and marketing) the unique qualities that make Jersey produce worth trying and buying? How can we reawaken a sense of pride amongst the whole community in Jersey?" (States of Jersey, 2007: n.p.). In this context of top-down branding, agriculture is foregrounded, along with finance, tourism and community, as one of the overarching features that the States of Jersey aims to promote in connection with standing for Jersey in a broader sense (other spheres of this branding exercise are discussed later). It is agricultural produce like this that are typically supported by Genuine Jersey, although the breadth of produce promoted by this public-private organization moves far beyond such traditional crops as the Jersey Royal Potato.

The growth of the post-Second World War tourist industry was primarily the result of an increased ability to travel during economic growth and increased amounts of leisure time. During this period, Jersey put itself forward as being sunny, close to France and having a social and cultural heritage that was unique amongst the British Isles (such as Norman influence, beaches around much of its coastline, low or no taxes, war artefacts), which attracted mass tourism from the UK. ${ }^{3}$ In this context, Jersey has histories that are well-known outside the island, reputations that allow some aspects of its past and present to be foregrounded and to stand for the island.

Jersey's beaches, of which the small island boasts many, as well as its physical landscape with small lanes, walking paths and sea views - offer the tourist industry various facets that have helped attract many tourists over the years. As noted in the recent corporate branding exercise:

\footnotetext{
${ }^{2}$ The Channel Islands, of which Jersey is the largest, are not actually geographically part of the archipelago of the British Isles, but rather islands that are very close geographically to the French mainland in northwestern Europe.

${ }^{3}$ As noted elsewhere (Johnson, 2010), Jersey makes much of its Norman heritage, particularly as one Norman island or location amongst others, and from various perspectives Jersey particularly showcases its unique island existence, including its dislocation from France and Britain, its cultural heritage, and its place as a tourist destination and finance centre. Indeed, Jersey is increasingly using aspects of its distinct island heritage in various branding exercises, including the use of the island's local language, Jèrriais, on the latest bank notes of the island's own currency (pegged to the Pound Sterling)
} 


\section{H. Johnson}

Jersey has always been a very beautiful, very desirable place to live and work. And it already has a 'brand': a set of perceptions that many people share about what Jersey is like. Safe, secure, beautiful, great beaches, a little old fashioned, off shore, Jersey Royals, wealthy, a bit inward looking. A whole mix of the good and bad, the fair and the unfair (States of Jersey, 2007: n.p.).

In this setting, the heyday of Jersey's mass tourism that dominated the island until around the 1990s witnessed a multitude of hotels and guest houses shaping the built-up parts of the island, with large hotel complexes surrounding several beaches, tour companies filling the roads with coaches, and the ever-present hire-car (Brychan \& Thomas 2012). Nevertheless:

Traditional Jersey industries such as agriculture and tourism were superseded by financial services as the dominant industry in Jersey. The financial services sector (which includes banking, trust and company administration, fund management, accountancy and legal activities) has grown such that it now accounts for almost half of total economic activity in Jersey and employs about a quarter of the workforce (States of Jersey Statistics Unit, 2010: iv).

Branding on Jersey, therefore, is undertaken in many ways. As a place, Jersey is known both for its individual industry sectors as noted above, and collectively for each of them as a way of representing the island. However, as discussed next, when place branding and goods' branding are combined in a public-private partnership, a different type of marketing dynamic is revealed with regard to the produce and products that form part of that brand vis-à-vis those that are not. Moreover, those goods that are accepted as part of such a brand might be viewed as part of a staging process or emergent authenticity that actually binds them to inauthentic experiences (Cohen, 1988: 373; MacCannell, 1999).

\section{Genuine Jersey and the Authentic Island}

\section{Purpose}

Jersey holds an enviable position amongst other small island jurisdictions and cultures in terms of the international recognition of several of its products and produce. Household and even global brands include Jersey milk (from the Jersey cow), the Jersey Royal Potato, the Jersey tomato, Jersey cabbage and broccoli. As discussed later in connection with place branding, most of these products include the word "Jersey" in their name, something that helps brand not only the items but also the island (as with Shetland wool and Orkney beef). Furthermore, these products are well known within and beyond their home island, and their long association with Jersey would have already created a reputation as part of an established island brand (Baldacchino, 2005: 29). Before finance became the dominant industry on the island, and also part of Jersey's contemporary brand, local produce such as those listed above helped form an important local and export industry. For much agricultural produce, Jersey's warmer climate in comparison to the other British Isles helped local traders ship their produce to the UK at the start of the season. While Jersey produce such as these remain in high demand, their place on the island and in the export industry has taken a slightly different role. That is, while they no 
longer form part of the main industry for most islanders, they still hold an important place as products for local and non-local consumers, as well as for their ability to stand for the island as part of its traditional past. Here, the island's heritage has been partly constructed around the reputation of its agricultural produce, and the preservation, and sometimes rediscovery, of some produce and products is found within the Genuine Jersey framework (Lichrou et al., 2010: 141).

Top-down branding exercises, such as the ones discussed by Grydehøj (2008: 175) in connection with Shetland and other islands, explore issues of generic island branding imposed on a "locally-oriented identity concept". In this setting, place branding serves to collectively give an island distinct characteristics that might help market the island to incoming tourists or locals or non-local consumers (Baldacchino, 2010b). The focus of this discussion, however, is on a Jersey organization whose sole purpose is to brand select local produce and products with a distinct label, "Genuine Jersey". As a non-profit marketing organization that is heavily supported by government (discussed below), Genuine Jersey works directly with many local businesses in order to help bring aspects of some island industries together to collectively brand unique features of Jersey (Genuine Jersey website). Genuine Jersey collaborates with such businesses by offering marketing advice and support, promoting members' brands by holding public events around the island, holding growing competitions such as the Genuine Jersey Royal Potato Growing Competition, ${ }^{4}$ and offering a branding logo (Figure 1) that members use when packaging, labeling and marketing their goods. In such a framework, Genuine Jersey offers a level of branding for local products that fall within its guidelines (discussed later). Such products might have a long history on the island, or they might be recently conceived in a broader commercial environment that is aligning itself with a notion of a Jersey brand as a way of achieving greater commercial advantage. As noted in more detail later, there are also products that may have an established place on the island, yet fail to be recognized by Genuine Jersey.

Figure 1: ‘Genuine Jersey’ Logo (Genuine Jersey, Branding Guidelines).

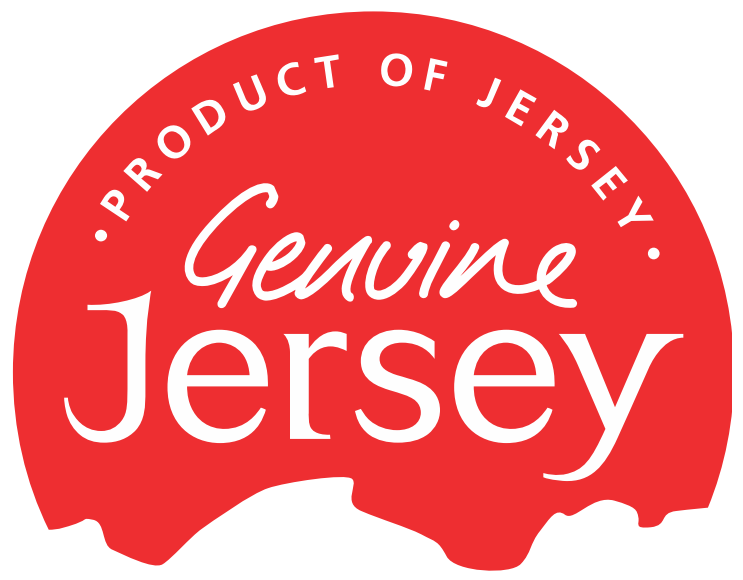

${ }^{4}$ Genuine Jersey also provides a Teacher's Pack for this competition (see Genuine Jersey, Education). 


\section{H. Johnson}

\section{Structure}

The organizational aspects of Genuine Jersey provide various links with Jersey's government, a government department and with local businesses, and a study of these interconnections helps show how the organization is able to exist in a public-private sphere and in connection with Jersey's small island political and commercial landscape. This public-private partnership allows government to collaborate through a series of organizations with local businesses, and for those businesses that are members of Genuine Jersey to indirectly draw on funding support that ultimately serves to help market their goods. ${ }^{5}$ Public funding through the States of Jersey Economic Development Department (Jersey Tourism is a part of this Department) is used to help some businesses promote their produce and products collectively under a shared brand that is inherently defined as local and authentic versus goods that are either imported, locallyproduced but do not meet the requirements of Genuine Jersey, or have not yet been offered to Genuine Jersey for consideration. Genuine Jersey's link with Jersey Tourism is very close. They share the same physical office space, and both are linked to the Department of Economic Development. It is this construction of a perceived island-centred authenticity that this discussion is mostly concerned with.

Launched in 2001 by several local businessmen "who wanted to be able to differentiate their product, which was locally produced, from product that was imported, but sometimes gave the impression that it was local" (Garton, 2011), Genuine Jersey Products Association (GJPA) interconnects a number of commercial and political affiliations, and Genuine Jersey is the brand name that is used in the public domain. Above this association there is now a company called Jersey Product Promotion Limited (JPPL), which was formed in 2008. At this time, GJPA became a subsidiary of JPPL, the latter of which is "wholly owned by a special purpose trust under the aegis of the States of Jersey Economic Development Department" (Genuine Jersey, Branding Guidelines: 1). ${ }^{6}$ One of JPPL's primary purposes is to employ Genuine Jersey's Chief Executive Officer, and also to take more control of the activities of GJPA. The direct connection with government is that JPPL receives an annual grant from the Economic Development Department, and this Department has outlined some strict criteria when awarding the grant. As noted by its Executive Director, who is also Chief Executive Officer of Genuine Jersey, JPPL is essentially to "promote local product both in the local market place and overseas" (States of Jersey, 2010a: 11; see also States of Jersey, 2010b). In 2010, for example, JPPL received $£ 140,000$ (about US\$217,000) from the Economic Development Department, half of which went to Genuine Jersey (States of Jersey, 2010a: 10). As well as this grant, Genuine Jersey receives office space and office equipment and fittings. When the differences between the various affiliations of Genuine Jersey are defined, in general terms, JPPL focuses on local product off island, and Genuine Jersey on local product on island, the latter being the focus of this discussion (States of Jersey, 2010a: 5). ${ }^{7}$

\footnotetext{
${ }^{5}$ Prior to Genuine Jersey, the States of Jersey ran a branding exercise known as "Jersey Fresh", which was funded entirely by the government.

${ }^{6}$ The embedded nature of Genuine Jersey in government policy is evident in such documents as the Rural Economy Strategy 2011-2015 (States of Jersey, 2010b) where Genuine Jersey is found in connection with "Marketing Support for Jersey Produce" (25) and "Working together and collaboration" (39-40).

${ }^{7}$ Some goods that do not comply with the Genuine Jersey guidelines form part of JPPL's marketing activities off shore.
} 
The Genuine Jersey Management Committee includes representation from government, government organizations, Genuine Jersey and local businesses. Its structure comprises the following positions: Chairman (independent), Vice-Chairman (independent), Chief Executive Officer, Committee Members (three from the scheme's membership and three from the Economic Development Department [one must be a Trading Standards Officer]), Associate from the Jersey Farmers' Union, and an Invited Arts and Crafts Representative. This structure and membership allows Genuine Jersey to be represented not only from government but also from key partnership organizations and business. The Chief Executive Officer, who is Executive Director of JPPL, is remunerated in this position and has the main day-to-day responsibility of the running of Genuine Jersey.

There are strict criteria for becoming a member and for using the Genuine Jersey branding logo once an annual payment has been made, as noted in its Charter:

2.6: In general, goods will qualify as being appropriate to carry the Genuine Jersey logo if they:

2.6.1: comply with all relevant legislation and the current assessment criteria applied by the Management Committee,

2.6.2: are designed and produced entirely in Jersey using exclusively local raw materials and skills,

2.6.3: are grown in Jersey from seed or acceptable imported stock

2.6.4: are designed and produced in Jersey not necessarily of local raw materials but where there is evidence of a level of skill and design showing the individuality of the designer/maker,

2.6.5: are produced in Jersey where a local component is the reason for the product being produced and using local skills in its production,

2.6.6: are produced, developed, grown or reared in Jersey from imported stock but where local skill, husbandry or some other distinctive element unique to Jersey plays the predominant role in production,

2.6.7: restaurants may apply for membership where they have dishes on the menu which contain at least $80 \%$ local ingredients. Such dishes only may be identified on the menu with a Genuine Jersey logo (Genuine Jersey, Charter). ${ }^{8}$

To become a member of Genuine Jersey, businesses must follow these criteria and pay an annual membership fee, and in doing so they are able to brand their goods using the Genuine Jersey logo. The emphasis on the goods is on the location of Jersey. That is, it is on the produce or product in terms of where it is grown, caught or made. The exception is in restaurants, where the dishes can have $20 \%$ non-local ingredients and still be eligible to join the organization. By varying the amount of non-local ingredients acceptable to become a member of Genuine Jersey, the organization is able to acquire further income from some of the numerous restaurants that are in Jersey, many of which service the tourist industry and the affluent culture that has emerged as a consequence of the finance industry. However, by

\footnotetext{
${ }^{8}$ Genuine Jersey based their criteria on a similar system used in Cornwall. Interestingly, this English county was described as being similar to an island: "Cornwall very much is ... in a way, an island community" (Garton, 2011).
} 


\section{H. Johnson}

reducing the criteria for the amount of non-local ingredients, questions are raised about broader aspects of membership. Should the membership criteria be the same for all businesses? Why should restaurants get such a reduction? What about other businesses that can only exist with a similar amount of imported items? In the modern-day globalized world, many businesses that may have roots in an island culture might rely in varying degrees on imported items. It is here that one can see the need for the organization to gain more members from representative spheres of island business, although in doing so the core of the "genuine" message is perhaps diminished when criteria are allowed to vary between businesses.

In terms of the authenticity of the goods that Genuine Jersey promotes, the organization clearly emphasizes the place of the island rather than the people producing the goods, although they should reside on Jersey. In doing so, a contradiction is revealed regarding the social place of production rather than the local place of production. For instance, the Jersey Royal Potato has been a traditional part of Jersey agriculture for many generations, but it is not always locals with many generations of Jersey ancestry that have been responsible for providing all the labour connected with farming this product. Jersey has a long history of importing short- and long-term agricultural migrant labour, as well as similar labour opportunities in other industries such as tourism and finance. The agricultural industry, for example, is known for its imported labour, first in terms of French workers, then Portuguese and more recently Polish. Likewise, the tourism industry, with its history of establishing a plethora of hotels and restaurants, has employed many migrant workers who have each contributed to the promotion of Jersey cuisine for local and tourist consumers. Other business too rely on Jersey's emerging multicultural labour force in the production of goods, each of which points to the emphasis on place in the promotion of Genuine Jersey goods rather than the people involved in their production. While the area of authenticity is also discussed later, comparisons can be made with the branding exercises of other islands. For example, Khamis (2011: 1) challenges the branding of the island of Lundy in the Bristol Channel in the UK as unspoiled or untouched: "this perception is highly misplaced, and fails to take stock of the considerable effort that goes into managing Lundy". In other words, Genuine Jersey seems to promote produce and products as part of a perceived authentic Jersey, something that represents the island in a kind of pure form (albeit with allowances made for some businesses). However, while Jersey in the present day has roots in its island heritage, the island is also part of a contemporary world of global flows with rapid movement of people, goods and information. Genuine Jersey may represent $a$ genuine Jersey, but does it truly represent the genuine Jersey?

The mantra of buying local allows Genuine Jersey to align itself with contemporary green politics. This is especially evident in public statements by Genuine Jersey where the importance of purchasing its members' products is placed in the context of potential environmental disasters:

It gives consumers the choice to mitigate the adverse affects of global warming by reducing their food miles and the Island's carbon footprint. Making an informed choice to buy local and embrace seasonality is good for the Island's economy as it supports local jobs and recycles the local pound. Keeping agricultural fields in production also ensures that the Island's countryside remains green (Garton, 2010: 2). 
The use of such a collective and public-private method of branding in Jersey reflects wider global trends that have seen the increased labelling of produce and products in terms of locality. The example suggested by Scherrer et al. (2009) of "Designation of Origin" labelling in the Canary Islands' wine industry and its connection with tourism is one example from an archipelago. The European Union has done much to try to ensure that goods with a recognized connection to a place are safeguarded against inauthentic use of the same name. This is "a status that recognizes these products to be authentic, quality, local products ... that are available to both locals and outside visitors looking for typical Canary Islands' foods" (Scherrer et al., 2009: 452; Sainz, 2002). Most importantly, in the same way that Genuine Jersey links island products and produce with the island itself, "Designation of Origin" operates by "highlighting originality and providing an authentic experience that links the local products with aspects of the landscape, the area's history and community in a holistic way" (Scherrer et al., 2009: 460). This type of branding might be viewed as protectionism where members' goods are given special status over other goods that attempt to link to the success of the original produce or product. For example, within the European Union there is a Protected Geographical Status (PGS) law that protects the naming rights of regional foods. For Genuine Jersey, however, the organization is collectively branding select island produce and products to show that they are genuinely local, rather than imported. This relates closely to the PGS law, although it does not exclusively lay claim to the name Jersey, but, rather, the location and manner in which the goods are produced.

The tropes of providing "pride for residents" and a "desire for visitors" (Genuine Jersey, Charter: 2) point to the provision of a brand that seeks to embody a sense of place in the goods it promotes. As noted by the Chief Executive Officer, Genuine Jersey is "trying to drive some level of quality into the product" (Garton, 2011). For the brand to succeed in the local market, islanders will need to take pride in it in comparison to imported or non-Genuine Jersey goods, and visitors will need to seek the brand as a memento of islandness during their short-term stay on Jersey (Figure 2). As noted by Jersey Tourism, "work continues to take place through the auspices of Genuine Jersey to encourage local producers to trade and to develop products so that visitors can take home a Genuine Jersey souvenir" (Jersey Tourism 2008: 10). It is here that Genuine Jersey points to the celebration of local and of members' goods vis-à-vis other goods. In such a context, membership of the organization becomes one of aligning a business and its goods with a brand that stands for Jersey, and only market research would be able to tell the success or lack of it in terms of whether it is beneficial for a business to become a member or not. There are indeed various businesses on Jersey whose goods are not recognized by Genuine Jersey, yet they claim to have very similar objectives. Take, for example, The Jersey Cow Company, which notes:

We endeavour to produce products of the highest quality at a price that makes them an 'everyday luxury indulgence'. The key to all of our products is 'purity \& provenance'. We will only create products that have a genuine link to the island and that are not only good for you but also good for the environment (The Jersey Cow Company). 


\section{H. Johnson}

Figure 2: 'Genuine Jersey’ Banners at Jersey Airport. (Photo by author.)

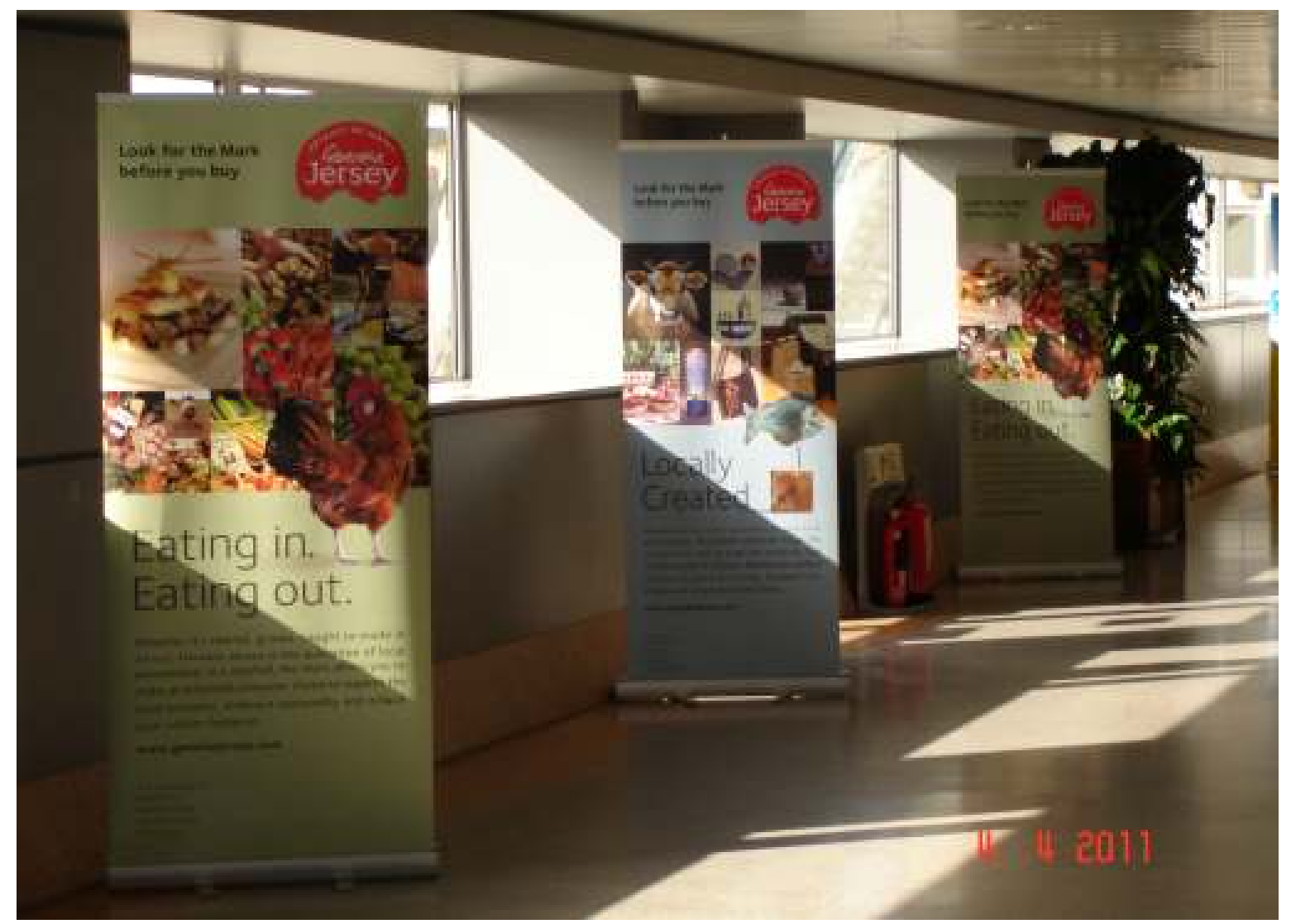

This company, as one example, has aims that are almost identical with those of Genuine Jersey, yet it is not a current member and thus is establishing its own brand. In such a context, some brands might actually be disassociating themselves with collective brands of the publicprivate type. Genuine Jersey has now been in existence for over ten years, and it has increased its membership on an annual basis. It is forming a brand that will suit the products and produce of some Jersey businesses and not others. In forging its overall membership, the organization is creating a division on the island regarding businesses that have an affiliation with Genuine Jersey and those that do not. Some businesses are not members either because they do not fulfill the selection criteria, or because they have chosen not to become affiliated with the organization. While such a topic is the study for future research, it will suffice to say here that the only main incentive in staying away from this brand, even if fulfilling membership criteria, would be in terms of being able to offer an alternative brand that has the ability to function in its own right and not associate itself with a collective based on authenticity.

Apart from government funding, Genuine Jersey receives income in the form of an annual fee from members and sponsors. In 2011, there were 91 members and seven sponsors (see Genuine Jersey, Our Members). Over the ten years of its existence (at the time of writing this article), Genuine Jersey has grown rapidly: 20 members in 2001; 60 members in 2005; and 91 members in 2011. While members' goods must qualify to gain labeling rights, in a somewhat contradictory way to the underpinning purpose of Genuine Jersey, sponsors simply pay an annual fee based on the size of the business, or a service for Genuine Jersey's members, and do 
not have to qualify first. In addition to the membership fee, the sponsors' scheme provides not only a further income stream for Genuine Jersey, but also further connections with the island's businesses. A reward from Genuine Jersey to its sponsors is the right to use the Genuine Jersey Sponsor mark, even though the business might not actually qualify to be a member (Genuine Jersey, Sponsors). There is obviously inconsistency of purpose in connection with products that comply with the Genuine Jersey membership criteria and sponsors who do not, yet the latter are still able to associate themselves with a brand that has authenticity of product at its core. This point of contention highlights how on the one hand a public-private partnership is able to function within the commercial market, yet on the other hand how commercialism can help undermine some of the core values underpinning the organization.

The point of difference with the Genuine Jersey brand is that it is simultaneously top-down and bottom-up in terms of its purpose, and is also a public-private partnership. While closely linked with a government department, on which it relies for considerable funding and infrastructural support, Genuine Jersey has a membership base of local companies and businesses that collectively identify with and use the Genuine Jersey logo and brand as a way of marketing their produce and products. As part of the funding agreement, the grant that Genuine Jersey receives is reduced each year, and is intended to be replaced by private funding. A consequence of this is that the number of sponsors is likely to increase, with the possibility that some may not fulfil the criteria for membership and therefore reducing the organization's overall association with businesses that reflect its primary purpose.

With such an organization, questions are raised when considering the incentives for local businesses to become members. What is in it for them? What if they don't join? As noted in its Charter, "the Genuine Jersey brand seeks to promote":

- Members' goods

- An informed choice for the consumer

- The retention of consumer spending in the local economy

- A pride for residents in the quality and diversity of the goods of their Island

- Visitors' desire to prolong memories of a Jersey holiday by buying Genuine Jersey goods

- An accord between participating businesses to enhance the brand and generate viable business for each other, without limiting consumer choice or imposing any price configuration on local goods

- Sustainability for and innovation amongst local producers

- A guarantee of compliance with all statutory requirements (Genuine Jersey, Charter: 2).

The Charter includes a number of key points intended for locals and visitors alike. While the underpinning purpose of the branding is surely to increase sales of members' goods as competition grows in local and global markets, and hence ensure the sustainability of the local economy with "the retention of consumer spending" (Genuine Jersey, Charter: 2), several of the Charter's points help show how the brand can embody meaning in other ways for consumers who purchase its goods. For example, by offering an "informed choice for the consumer" (Genuine Jersey, Charter: 2), Genuine Jersey goods are immediately juxtaposed with others that do not include the brand mark. This type of branding shows a labeling that embodies a notion of authenticity at its core. That is, Genuine Jersey goods represent a 


\section{H. Johnson}

"genuine" Jersey, others, therefore, do not. But such a constructed type of authenticity of place also serves to render the brand inauthentic because the image is created, or at least reinforced, by the brand in the first place.

\section{Logo}

The purpose of any branding exercise, whether initiated by a government organization or a private company, is to offer a product with which people might easily identify and recognize. As one researcher has commented:

Today it is argued that not only should products and services develop a system of brand management focused on their identity, which helps develop a coherent execution, but places should also develop a similar brand management system (Freire, 2009: 420).

Jersey Tourism, for example, would brand itself and the island of Jersey for slightly different purposes than a local retailer, although there might be similarities in terms of the desired targeted market. A prominent feature of most contemporary branding exercises is the inclusion of a logo, which acts as a visual signifier that is usually easily understood and remembered (Klein, 2000). For example, Jersey Tourism has recently introduced its "golden bird" logo (see top right of Jersey Black Butter poster in Figure 3), which is used as an emblem for the island in terms of its recognition as a tourist destination (States of Jersey, 2007: n.p.). The "golden bird", which has also been described by unconvinced locals as a "flying banana" (e.g. Lewis, 2007: n.p.), was a $£ 250,000$ exercise (Quérée, 2007: n.p.), and is intended to represent "Jersey's sense of independent spirit and freedom, the richness of its culture and all its produce, and its fresh outlook for the future" (States of Jersey, 2007: n.p.).

\section{Figure 3: Shop at Jersey Airport. (Photo by author.)}

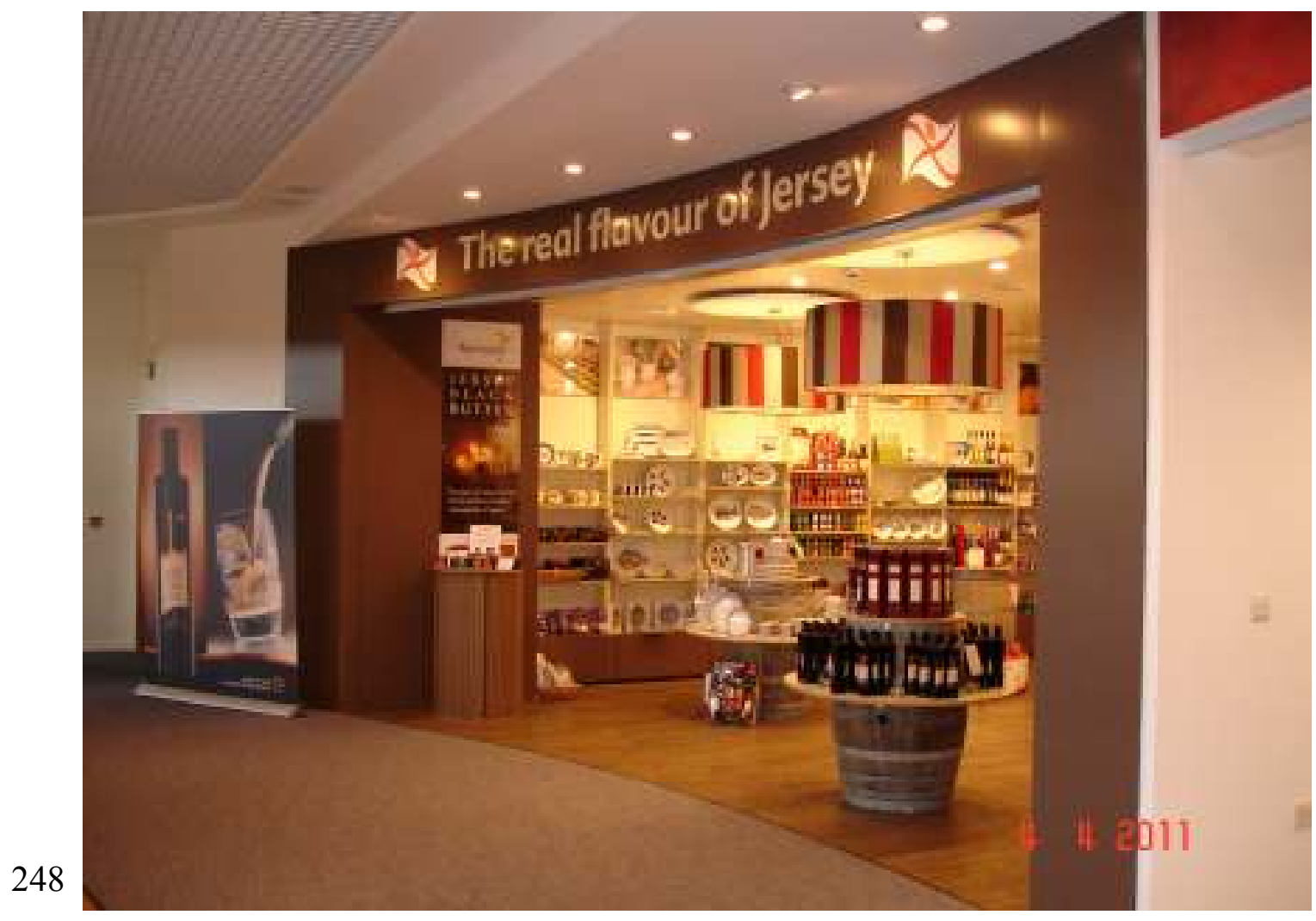


Genuine Jersey too offers a logo as well as several slogans that inherently index a sense of authenticity in the language that is used. ${ }^{9}$ With the requirements of members' produce and products having to fulfil strict criteria in terms of showing how they are locally produced, the notion of authenticity is both inscribed in the goods themselves and also ascribed to them. The single aspect of branding these goods involves becoming a member of Genuine Jersey and being privileged to use its logo and branding network. Genuine Jersey provides extensive guidelines for the use of its logo and in its Charter notes that it is:

- an endorsement of the goods' own brand or trade mark,

- awarded only to those goods which fulfil both the spirit and the word of the Genuine Jersey Charter,

- available in various regulated colours to achieve compatibility with goods,

- used only in accordance with strict guidelines which are subject to regular review (Genuine Jersey, Charter: 2).

Genuine Jersey might be seen to justify its existence by establishing itself against inauthentic brands being sold on Jersey that give the outward impression that they are a product of local traders, but in reality have been produced in part or entirely outside the island. One example of this that was offered to me during research was that of Jersey fudge being sold at Jersey Airport, a context ripe with touristic merchandise and a place where the visitor is able to purchase a lasting memento of the island. One particular brand gave the outward appearance of representing the island and was labeled "Jersey Fudge", yet it was produced in China (Garton, 2011). Another brand, however, Sue's Fudge, offers the consumer "real Jersey fudge" and is recognized by Genuine Jersey.

Authenticity (i.e. 'genuineness') for Genuine Jersey is about speaking what it perceives as the truth about local produce and products; Genuine Jersey makes a statement about the island and for its members' goods. In this context, "genuine" stands for Jersey, its provenance, and the brand has the infrastructure and governmental and establishment links to ensure that it makes an impact on the island for local businesses. Here, a sense of nationalism and localism (as well as island identity) is embodied in the Genuine Jersey logo, where "authenticity ... is constructed by cultural representation and media techniques, which makes it an inter-subjective discourse but therefore no illusion" (Fornäs, 1995: 219). It is in this context that "image makers and the media assume a more powerful role in the shaping of political identities" (Harvey, 1990: 289). By grouping different goods under one umbrella brand, or rather allowing different businesses to use its logo after payment to become members of the organization, Genuine Jersey is constructing a sense of "object-related authenticity", the "cognitive experience of the authenticity" (Ivanovic, 2008: 322). While "authenticity is a socially constructed concept" (Ivanovic, 2008: 323), the branding process would aim to achieve a higher level of desire for the goods being branded (Wang, 1999). Ironically, of course, such staged authenticity would actually be "damned to inauthenticity" (Cohen, 1988: 373; MacCannell, 1999). Furthermore, the Genuine Jersey brand groups a number of disparate goods under one label, which allows some goods to attain the status of authentic and to be

\footnotetext{
${ }^{9}$ Guernsey, the second largest of the Channel Islands, introduced a "Guernsey Grown" label in 2008 for local agricultural produce of members of the Guernsey Growers' Association (de Woolfson, 2008).
} 


\section{H. Johnson}

associated with produce and products that have a longer recognized history on the island, such as the Jersey Royal Potato, cow or tomato (Baldacchino, 2005: 29-31).

To make the point even stronger, in its advertising campaigns Genuine Jersey asks the consumer to "Look for the logo before you buy" (Advertising flyer), and "Look for the Mark before you buy" (Advertising flyer). The same flyer offers six reasons why the consumer should buy local Genuine Jersey produce, which are:

- Eat seasonally

- Support local agriculture

- Reduce food miles

- Preserve the environment

- Support the local economy

- Provenance/traceability (Advertising flyer).

The language of authenticity in the term "genuine" offers an implied opposite: that which is not genuine. This use of implied linguistic "othering" does much to reinforce Genuine Jersey goods as ones that are truly representative of Jersey and ones that locals and visitors should purchase, whether to support local businesses or as a marker of remembrance. ${ }^{10}$

The inclusion of the name "Jersey" in the Genuine Jersey logo does much to convey the island as part of the product (see States of Jersey, 2010a: 33-34). The "island lure" (Baldacchino, 2010a) is inherent in the logo and therefore in the produce and products the organization supports. While Kotler (2004: 12) notes that "places are more difficult to brand than products", the Genuine Jersey brand offers a way of combining the two. The inclusion of the name of the island itself in Genuine Jersey branding offers a powerful way of simultaneously place branding and product/produce branding (Anholt, 2008; Hanna \& Rowley, 2008). Compare, for example, the "New Zealand, 100\%" branding exercise that was launched in 1999 (Morgan et al., 2002), which also offers a powerful linguistic message entwined in ideas of authenticity and place branding in connection with the promotion of the country as a green and clean place to visit. ${ }^{11}$

Furthermore, the Genuine Jersey logo mentions Jersey twice. First, along the top of the almost semi-circular logo the text "Product of Jersey" is written; and second, "Genuine Jersey" features as the main central wording. Linking "product", "genuine" and "Jersey" in this way reinforces the sense of the item having an authentic content, and the more goods that carry this mark then the more the idea is strengthened in comparison with goods that do not carry the mark. Moreover, not only is the term Jersey part of the overall brand, but several businesses that belong to Genuine Jersey also have the term in the title of their business or produce (Genuine Jersey, Products).

\footnotetext{
${ }^{10}$ A related sense of authenticity is offered by Jersey Tourism in their "Pure Jersey" campaign in which some Genuine Jersey goods are featured (Jersey Tourism, 2011).

${ }^{11}$ There is also an example offered in the branding guides (States of Jersey, 2007) where the Genuine Jersey logo and golden bird are placed together, thus presenting a product/produce brand logo simultaneously with the one that represents the island.
} 
Another symbolic aspect of the logo is found in terms of its shape. While it has been designed so that the text occupies the upper part of an almost semi-circular mark, what is particularly symbolic about the shape of the lower line on the logo, which consists of a wavy or jagged line across the centre, is that this can be seen to represent part of Jersey's ragged coastline. This is another inherent aspect of the brand that allows it to stand for the island in various linguistic and non-verbal ways, and to encompass place branding simultaneously with goods' branding.

\section{Activities}

Genuine Jersey goods are found in many retail and public contexts. Not only do individual businesses have their own sites and mechanisms to market or sell their goods, but there are several other public contexts that do much to promote specifically Genuine Jersey products and produce. These include two shops that specialize in Genuine Jersey goods, and public events where products and produce are showcased and sold to the wider local and visiting public. Genuine Jersey has also been active in several events that reward its members, and also entice non-members to take a more active role in the organization. As noted in one of its press releases:

Nominations are being sought for three awards, namely 'Best New Genuine Jersey Product or Initiative', 'Member of the Year' and 'Genuine Jersey Retailer of the Year'. The first two awards are open to the Association's membership, which now totals almost 60 local businesses. The third award is specifically for non-member businesses only. (Genuine Jersey Products Association, 2005).

One of Genuine Jersey's founding members, La Mare Wine Estate, opened a shop in Jersey's capital, St. Helier, in 2004. The shop, which is called Maison La Mare, also sells produce belonging to other Genuine Jersey members (Genuine Jersey Products Association, 2004a). The shop is located on King Street, which is a pedestrian precinct at the heart of Jersey's retail district. Its prominent red façade along with its French name make it particularly noticeable amongst many other shops with mainly English names. Indeed, it is perhaps the shop's French name that adds a further aspect of foregrounding Jersey in terms of its geographic proximity to mainland France. Jersey makes much of its French and Norman connections, so for the visiting tourist the shop becomes a symbol for these links.

One retail site that occupies the gaze of locals and tourists alike is the shop at Jersey Airport called "The Real Flavour of Jersey" (Figure 3). The shop is a collaboration between The Jersey Pottery and La Mare Wine Estate, both members of Genuine Jersey. The shop sells some items with the Genuine Jersey logo on them, and its name further emphasizes the branding of local goods in an authentic way. Here, the "real flavour of Jersey" offers a point of reference that, like the term "Genuine Jersey", creates a hidden signifier of an "other": that is, goods that are inauthentic (i.e. non-members). Further features of the shop include its use of two Jersey flags, which are further signifiers of localness, along with several low-lying light shades that have stripes that are reminiscent of those on the French flag (Figure 3). Interestingly, another wellknown Jersey business, Jersey Pearl, has a shop at Jersey Airport just by "The Real Flavour of Jersey", although Jersey Pearl, whilst offering a brand that claims Jersey and the pearl as its own, is not a member of Genuine Jersey, presumably because of its pearls being imported to 


\section{H. Johnson}

the island. However, Jersey Silver Plating is a member of Genuine Jersey, and it is based in the Jersey Pearl building.

Apart from these retail outlets, there are several regular or annual events where Genuine Jersey goods are promoted to the wider public around the island. These include the Jersey Farm and Craft Market (during July and August), St Aubin Farmers and Crafts Market and St Aubin Food Fair. Also, a special Christmas market is held a few days before Christmas (Hathaway, n.d.). While Genuine Jersey is involved with helping local businesses brand their products or produce, it also sponsors events such as the St Aubin Food Fair. This fair is the highlight of the Jersey Tourism “A Taste of Jersey in Autumn" week. In 2002, the event attracted over 10,000 people (Genuine Jersey Products Association, 2004b), and in 2003 the figure was estimated at 18 to 20,000 people (British Tourist Authority, 2003: 16).

Other market events that feature Genuine Jersey goods include the Saturday markets run by Jersey Turbot at St Catherine's; a Genuine Jersey village market as part of the Jersey Evening Post West Show; and Christmas fairs held at Jersey Pottery as part of Jersey Tourism's La Fête dé Noué (Christmas fête).

Each of the public events noted above are sites where Genuine Jersey goods are put on show to potential consumers. The events are intended for locals and tourists alike, with the majority taking place during peak tourist season. In each, Genuine Jersey is able to take preference over other traders' goods, set up stalls and promote its members' goods, or organize the events for the main purpose of promoting the products and produce of the businesses it represents. There is a distinct sense of Genuine Jersey goods at many of these events in that the brand is sometimes displayed collectively on the same stands. With these events, the government is indirectly involved in funding much of Genuine Jersey's activities, and thus gives some local businesses support at such events over other businesses who are not members of the organization (States of Jersey, 2010a: 32-33). The brand's success in this context is that it has become a wider part of island life: it is from the island, about the island and for the island. As noted by the Chief Executive Officer when asked about Genuine Jersey's biggest achievement over the past decade: "it's managed to integrate itself into the island ... it's become a part of everyday life ... it's trusted ... and ... [it] is authentic" (Garton, 2011). This statement is supported by the growth of Genuine Jersey over more than ten years: gaining more members, receiving more sponsorship, and broadening its public activities and events around the island for locals and tourists alike.

\section{Conclusion}

This paper has discussed Genuine Jersey as an example of a public-private organization in a small island context that exists to generate, maintain and strengthen a distinctly powerful Jersey brand. Genuine Jersey celebrates and constructs notions of authenticity, and interconnects business and government, either directly or indirectly. The discussion has shown how this organization brands Jersey produce and products within a framework of adding "island value" that either builds on consolidating recognized traditional island goods within its marketing campaign, or bringing in other goods that fulfil the requirements of being included 
and therefore linking them with notions of authenticity in being representative of Jersey as the place of production. Members' goods are approved to be authentically, genuinely Jersey.

As an organization, Genuine Jersey's unique place as a public-private partnership allows it to receive government support, which indirectly helps promote its members' goods. The case study has shown that Genuine Jersey is simultaneously involved in place branding in connection with Jersey, and with goods branding in connection with the produce and products of its members, some of which also include the word Jersey in their name. In doing so, the organization helps preserve goods that have long been considered traditional, and sometimes rediscovers or even invents a notion of authenticity for others within this framework. Extending the topic of the discussion even further, in the context of this paper the branding exercise has focuses entirely on produce and products (i.e. tangible items), but at a time when the global finance industry is dominating so much of the island's current income, one wonders if the label "genuine" could be applied to intangible outputs too? This is obviously beyond the scope of the current paper, but in a context where branding the island in a public-private partnership has taken on the role of place branding with an aspect of perceived authenticity inherent in membership and sponsorship criteria, questions should be asked regarding not only that criteria but also of tangible and intangible aspects of island culture that are currently not included in the Genuine Jersey brand.

While Jersey is increasingly inventing homogenous and disparate brands for itself, particularly within its three main industries - agriculture, tourism and finance - Genuine Jersey itself has crafted its own way for standing for the island. That is, it has helped to socially construct a perception of authentic goods in a marketing and branding exercise that at the same time creates an island-based value proposition with an othering of the goods of non-members (both locally produced and imported).

\section{Acknowledgements}

I am particularly grateful to John Garton, Chief Executive Officer of Genuine Jersey (Genuine Jersey Products Association) for making time to be interviewed as part of the research process.

\section{References}

Anholt, S. (2008) 'Place Branding: Is it Marketing, or Isn't it?', Place Branding and Public Diplomacy, Vol. 4, No. 1, pp. 1-6.

Askegaard, S. \& Kjeldgaard, D. (2007) 'Here, There, and Everywhere: Place Branding and Gastronomical Globalization in a Macromarketing Perspective', Journal of Macromarketing, Vol. 27, No. 2, pp. 138-147.

Baldacchino, G. (2005) 'Successful Small-Scale Manufacturing from Small Islands: Comparing Firms Benefiting from Locally Available Raw Material Input', Journal of Small Business \& Entrepreneurship, Vol. 18, No. 1, pp. 21-38. 


\section{H. Johnson}

Baldacchino, G. (2010a) 'Editorial: The Island Lure', International Journal of Entrepreneurship \& Small Business, Vol. 9, No. 4, pp. 373-377.

Baldacchino, G. (2010b) 'Island Brands and "The Island" as a Brand: Insights from Immigrant Entrepreneurs on Prince Edward Island', International Journal of Entrepreneurship \& Small Business, Vol. 9, No. 4, pp. 378-393.

Baldacchino, G. (2010c) 'Islands and Beers: Toasting a Discriminatory Approach to Small Island Manufacturing', Asia Pacific Viewpoint, Vol. 51, No. 1, pp. 61-72.

British Tourist Authority (2003) Food and Drink in Britain, London, VisitBritain in association with Food from Britain.

Brychan, T. \& S. Thomas. (2012) 'Cultural Events and Tourism in Jersey', Shima: The International Journal of Research into Island Cultures, Vol. 6, No. 1, pp. 114-131.

Cohen, E. (1988) 'Authenticity and Commoditization in Tourism', Annals of Tourism Research, Vol. 15, No. 3, pp. 371-386.

Corporate Edge Branding (2008) Jersey: Location Brand, http://corporateedge.com/articles/view/8

de Woolfson, J. (2008) 'Local Produce to get Guernsey Grown Labels', This is Guernsey, www.thisisguernsey.com/2008/05/16/local-produce-to-get-guernsey-grown-labels .

Fornäs, J. (1995) Cultural Theory and Late Modernity, London, Sage.

Freire, J.R. (2009) "'Local People”: A Critical Dimension for Place Brands', Journal of Brand Management, Vol. 16, No. 7, pp. 420-438.

Garton, J. (2010) 'The Future is Green with Genuine Jersey', in Environment Update, Vol. 3, St. Helier, States of Jersey Planning and Environment Department, p. 2.

Garton, J. (2011) Interview by Henry Johnson. 26 May.

Genuine Jersey - Application Form, www.genuinejersey.com/documents/GJPAApplicationForm2011.pdf

Genuine Jersey - Branding Guidelines, www.genuinejersey.com

Genuine Jersey - Charter, www.genuinejersey.com/documents/GJPANewCharterReleaseDec08.doc 
Genuine Jersey - Education, www.genuinejersey.com/education.htm

Genuine Jersey - Our Members, www.genuinejersey.com/members.htm

Genuine Jersey - Products, www.genuinejersey.com/products.htm

Genuine Jersey - Sponsors, www.genuinejersey.com/sponsors.htm

Genuine Jersey Products Association (2004a) Press Release, 21 July, www.genuinejersey.com/press.htm

Genuine Jersey Products Association (2004b) Press Release, 6 September, www.genuinejersey.com/press.htm

Genuine Jersey Products Association (2005) Press Release, 17 August, www.genuinejersey.com/press.htm

Grydehøj, A. (2008) 'Branding from Above: Generic Cultural Branding in Shetland and Other Islands', Island Studies Journal, Vol. 3, No. 2, pp. 175-198.

Grydehøj, A. (2010) 'Uninherited Heritage: Tradition and Heritage Production in Shetland, Åland and Svalbard', International Journal of Heritage Studies, Vol. 16, Nos. 1-2, pp. 77-89.

Hanna, S. \& Rowley, J. (2008) 'An Analysis of Terminology use in Place Branding', Place Branding and Public Diplomacy, Vol. 4, No. 1, pp. 61-75.

Harvey, D. (1990) The Condition of Postmodernity: An Enquiry into the Origins of Cultural Change, Oxford, Blackwell.

Hathaway, J. (n.d.) 'Christmas Market: St. Aubin Farm \& Craft Christmas Market', La Baguette, www.labaguette.org.je/April11.php? $\mathrm{p}=2191232$.

Ivanovic, M. (2008) Cultural Tourism, Cape Town, Juta.

Jersey Tourism (2008) A Year in Review, St. Helier, Jersey Tourism.

Jersey Tourism (2011) Pure Jersey, St. Helier, Jersey Tourism.

Johnson, H. (2010) 'Branding Jèrri: Art, Image, and Identity in Contexts that Celebrate Jersey's Norman Heritage', in A. Grydehøj (ed.) Refereed Papers from the 6th International Small Island Cultures Conference, Guernsey, 23-25 June. Lismore, The Small Islands Cultures Research Initiative, pp. 13-24. 


\section{H. Johnson}

Kelman, I. (2007) 'Sustainable Livelihoods from Natural Heritage on Islands', Island Studies Journal, Vol. 2, No. 1, pp. 101-114.

Khamis, S. (2010) 'An Image Worth Bottling: The Branding of King Island Cloud Juice', International Journal of Entrepreneurship \& Small Business, Vol. 9, No. 4, pp. 434-446.

Khamis, S. (2011) "Lundy's Hard Work": Branding, Biodiversity and a "Unique Island Experience"', Shima, Vol. 5, No. 1, pp. 1-23.

Klein, N. (2000) No Logo: Taking Aim at the Brand Bullies, New York, Picador.

Kotler, P. (2004) 'Where is Place Branding Heading', Place Branding, Vol. 1, No. 1, pp. 1235.

Kavaratzis, M. (2007) 'From City Marketing to City Branding: An Interdisciplinary Analysis with Reference to Amsterdam, Budapest and Athens', $\mathrm{PhD}$ thesis, Groningen, The Netherlands, the University of Groningen.

Leseure, M. (2010) 'Exploitation versus Exploration in Island Economies: A Brand Diagnostic Perspective', International Journal of Entrepreneurship \& Small Business, Vol. 9, No. 4, pp. 463-480.

Lewis, A. (2007) 'States Press on with "Banana" Logo', This is Jersey, 16 June, www.thisisjersey.com

Lichrou, M, O’Malley, L. \& Patterson, M. (2010) 'Narratives of a Tourism Destination: Local Particularities and their Implications for Place Marketing and Branding', Place Branding and Public Diplomacy, Vol. 6, No. 2, pp. 134-144.

MacCannell, D. (1999) The Tourist: A New Theory of the Leisure Class. Foreword by L.R. Lippard, Berkeley CA, University of California Press.

Manniche, J. \& Larsen, K.T. (2009) Firm-level Knowledge Dynamics of Creating Bornholm Food, EURODITE WP6 Report, Bornholm, Denmark, Centre for Regional \& Tourism Research.

Manniche, J, Larsen, K.T. \& Petersen, T. (2009) Development and Branding of 'Regional Food' of Bornholm. Final EURODITE WP5 Report, Bornholm, Denmark, Centre for Regional \& Tourism Research.

Morgan, N., Pritchard, A. \& Piggott, R. (2002) 'New Zealand, 100\% Pure: The Creation of a Powerful Niche Destination Brand', Brand Management, Vol. 9, Nos. 4-5, pp. 335-354. 
Parke, C.N. (2002) Biography: Writing Lives, New York, Routledge.

Pounder, P. (2010) 'Branding: A Caribbean Perspective on Rum Manufacturing Competitiveness', International Journal of Entrepreneurship and Small Business, Vol. 9, No. 4, pp. 394-406.

Quérée, B. (2007) “'So What Do You Think of Us Now, Chief Minister?', This is Jersey, 20 July, www.thisisjersey.com

Reddy, M. \& Singh, G. (2010) 'Branding of Fiji's Bottled Water: Edging into Sustainable Consumption', International Journal of Entrepreneurship and Small Business, Vol. 9, No. 4, pp. 447-462.

Sainz, H. (2002) 'Alimentos y bebidas con denominaciones de origen y distintivos de calidad: balances y perspectivas', Distribución y Consumo, July-August, pp. 58-73, www.mercasa.es/files/multimedios/1297893230_DYC_2002_64_58_68.pdf

Scherrer, P., Alonso, A. \& Sheridan, L. (2009) 'Expanding the Destination Image: Wine Tourism in the Canary Islands', International Journal of Tourism Research, Vol. 11, No. 5, pp. 451-463.

States of Jersey, Jersey Facts and Figures, www.gov.je/Jersey/Pages/Profile.aspx .

States of Jersey (2007) Jersey Brand Identity Guides, www2.jersey.com/brand

States of Jersey (2010a) Economic Affairs Scrutiny Panel, Rural Economy Strategy 2011-2015 Review, St. Helier, States of Jersey.

States of Jersey (2010b) Rural Economy Strategy: Sub-panel, Rural Economy Strategy 20112015, St. Helier, Economic Development Planning and Environment.

States of Jersey Statistics Unit (2002) Report on the 2001 Census: Jersey, St. Helier, Statistics Unit.

States of Jersey Statistics Unit (2010) Jersey in Figures, 2010, St. Helier, Statistics Unit.

States of Jersey Statistics Unit (2012) Report on the 2011 Jersey Census. St Helier, Statistics Unit.

Sue's Fudge. Real Jersey Fudge, www.suesfudge.co.uk/index.htm

The Jersey Cow Company, www.thejerseycowcompany.com/our_story

The West Show Association, www.westshow.org.je/Participation.aspx? section=takepart local\&footnote $=0$ 
Wang, N. (1999) 'Rethinking Authenticity in Tourism Experiences', Annals of Tourism Research, Vol. 26, No. 2, pp. 349-370. 